\title{
Territorio de conflicto: lenguaje e infancia en dos filmes latinoamericanos ${ }^{1}$
}

\section{Territory of Conflict: Language and Childhood in Two Latin American Films}

\author{
Catalina Donoso \\ Instituto de la Comunicación e Imagen, Universidad de Chile \\ catalina.donoso@u.uchile.cl
}

\section{Resumen}

El presente artículo se propone explorar la relación entre la construcción de la infancia como concepto y las problemáticas socioculturales asociadas a la adquisición del lenguaje. A lo largo del análisis se estudian los filmes Shunko (1960) de Lautaro Murúa y Dungún, la lengua (2012) de Pamela Pequeño, que además integran la presencia de personajes indígenas como tercera variable en juego. En el análisis se intenta reconocer de qué manera los filmes evidencian, a través de sus decisiones narrativas y del uso de la traducción como elemento significante -en ambos casos el subtitulado- el conflicto subyacente entre infancia, lengua y sujeto colonial.

Palabras clave: infancia, lenguaje, cine, sujeto colonial.

\section{Abstract}

The present article proposes an exploration of the link between childhood as a cultural concept, and sociocultural issues related to language acquisition. Two films are examined: Shunko (1960) by Lautaro Murúa and Dungún, la lengua (2012) by Pamela Pequeño, both films involve indigenous people main characters. The analysis focuses on how the films show, through their narrative strategies and the use of subtitles as a translation tool, the subtle conflict between childhood, language and colonial subject.

Keywords: Childhood, Language, Cinema, Colonial Subject.

1 Este artículo tiene su origen en el proyecto "Hogar y vagabundeo: estrategias narrativas de representación de la infancia en la novela y el cine chilenos contemporáneos”, financiado por Fondecyt Iniciación, Proyecto No 11121528. 
Probablemente una de las cintas más indicadas para analizar la relación entre infancia y adquisición del lenguaje sea el documental Poto y Cabengo (1980) del director de origen francés Jean-Pierre Gorin. Este filme recoge la historia de dos gemelas que aparentemente crearon y conservaron un lenguaje propio ${ }^{2}$ hasta aproximadamente los siete años. Su título hace referencia a los nombres que las niñas se otorgaron una a la otra en este idiolecto misterioso y de ritmo cortante con el que se comunicaron en la primera etapa de sus vidas. Poto y Cabengo es una pieza fílmica que también reflexiona sobre su propia representación y que utiliza en repetidas ocasiones los subtítulos en conjunción con las imágenes, e incluso la inserción de cuadros completamente negros acompañando al audio o intervenidos por letras en blanco, poniendo así en relieve también la cualidad visual del lenguaje. Con la utilización de este tipo de recursos, la película se desprende de la pura ilustración de una anécdota curiosa, para indagar en los aspectos sociales y culturales vinculados al lenguaje. En palabras de Bill Nichols:

Gorin no está tan interesado en obtener una "respuesta" a la pregunta del estatus del lenguaje de los gemelos o en observar cómo afectan los medios de comunicación a la vida de esta familia (como se puede ver en Happy Mother's Day, de Richard Leacock, sobre los quintillizos Dion) como en meditar acerca de la naturaleza del lenguaje y la representación como fenómeno social en general. (98)

La historia se estructura, entonces, cruzada por una serie de alcances más o menos explícitos en el filme, relacionados con la inscripción sociocultural de los padres, la precariedad lingüística del inmigrante encarnada principalmente en la abuela, los espacios de poder establecidos también en el terreno de lo íntimo, e incluso la propia experiencia del autor como un francés radicado en Estados Unidos.

Este ejemplo con el que inicio el presente texto, sirve sobre todo para ilustrar el escenario problemático en el que se instala el lenguaje como herramienta de modelamiento cultural y las instancias conflictivas que se suscitan en el proceso de su aprendizaje, situado fundamentalmente en la infancia, o al menos vinculado a ella. Estas ideas son un punto de partida para lo que me interesa explorar en este trabajo: situar a la infancia como lugar de exposición obligada a la norma lingüística, donde se exhiben claramente sus aspectos más complejos y revisar un par de cintas latinoamericanas donde se observan algunos de estos problemas. Lo que intento reforzar es la conceptualización del infante como territorio y tiempo de la adquisición del lenguaje, como instancia en la que el aparataje de la lengua se muestra en su proceso de hacerse propio. Esto como punto de partida, ya que en una segunda instancia me propongo integrar otro elemento, que postulo como relevante para el análisis de las cintas que trato, que se vincula también con los procesos de integración del lenguaje y que ya fue insinuado en la presentación del documental de Gorin. En los dos casos

2 Es común que los gemelos desarrollen un sistema propio y exclusivo de comunicación, pero suelen perderlo a temprana edad, cuando son capaces de dominar más cabalmente su lengua materna. 
a estudiar, los actores o personajes hacen uso esporádico de una lengua vernácula no manejada por el público al cual la cinta se dirige, y en la que el subtitulado funciona como ortopedia de esa lengua minoritaria, pero también como signo integrado al paisaje visual de la película. El uso de subtítulos -y del doblaje en otros casos- suele ser comúnmente considerado solamente como un elemento utilitario, despojado de significancia. La lectura que quiero hacer aquí es una que le otorga relevancia a su materialidad y a su sentido, buscando establecer conexiones con las reflexiones acerca de lenguaje y la infancia más arriba expresadas. En el documental de Gorin, el uso de subtítulos, funciona no tanto como herramienta de traducción, sino como material estético que pone en relevancia las problemáticas socioculturales asociadas a la incorporación de un lenguaje, y es desde allí que me interesa seguir explorando la relación entre infancia y lengua.

\section{El infierno en la palabra}

Antes de iniciar el trabajo de análisis propiamente tal, quisiera hacer una breve referencia a la escena de un filme brasileño, perteneciente a lo que se conoció como Cinema Novo -corriente cinematográfica gravitante que constituyó radicalmente el movimiento denominado Nuevo cine latinoamericano en las décadas del sesenta y setenta- donde se grafica el proceso que acabo de describir acerca de la infancia y su relación problemática con el lenguaje, y que puede servir como contrapunto para el ya referido trabajo de Gorin. Se trata de Vidas Secas, adaptación de la novela de Graciliano Ramos llevada al cine por Nelson Pereira Dos Santos en 1963. Una de las características de esta cinta es su economía de lenguaje. Los personajes hablan poco y callan mucho, y el sonido ambiente cobra gran relevancia a la hora de crear un escenario de carencia y desolación. Perdidos en un paisaje inhóspito, los miembros de la familia protagonista peregrinan en busca de trabajo y un lugar donde establecerse. En la primera parte de la película, aproximadamente hasta el minuto 18, antes de que lleguen a su primer destino donde el padre de familia encontrará un medio de sustento, prácticamente no hay diálogos, sólo hay textos excepcionales ${ }^{3}$. De allí que la significancia de los diálogos, cuando los hay, sea tan preponderante.

La que me interesa examinar aquí es una de las pocas secuencias en las que el niño mayor habla (el menor no lo hace nunca). De hecho, es la única escena en la que su discurso es protagónico. Tras la noche que el padre pasa en la cárcel, una curandera llega hasta el rancho para curarle las heridas con yerbas y oraciones. En

3 Una de las escenas que marcan este paso entre la errancia y la detención es aquella en la que el padre y la madre, tras haber hecho el viaje prácticamente sin dirigirse la palabra, inician un diálogo verborreico, que es más bien un monólogo a dos voces, con textos que se superponen, donde los enunciados no se responden ni se corresponden unos a otros, en una suerte de metáfora de la abundancia, reflejada en el aguacero que entonces cae, versus la sequedad de la tierra y su futuro incierto. 
uno de esos rezos, la vieja repite "al infierno". Mientras la madre cocina, el niño se dirige a ella y le pregunta qué significa la palabra "infierno". Ella responde que es "un lugar horrible, donde van los condenados, donde hay fuego y calderas hirvientes". El niño le pregunta si ella ha estado alguna vez ahí y la madre lo golpea. El hijo sale al patio, humillado, y a la vez cargado con esta nueva palabra que poner en práctica bajo la escasa sombra de un árbol sin ramas. "Infierno", repite, mientras una cámara subjetiva muestra su casa, "calderas hirvientes", dice, y vemos el cerro que corona el paisaje, "condenados", y aparece la madre asomada a la ventana. "Infierno", repite ocho veces más, internalizando el vocablo recién adquirido, dotándolo de connotación y describiendo, de manera precisa y directa, su paisaje interior.

Esta escena retrata de modo interesante el proceso de integración del lenguaje, en un contexto de tensiones, más que sociales, vitales. La palabra infierno es desconocida para el niño, la madre le entrega cierta información acerca de lo que el término refiere, pero su manejo relativo del vocablo -ya que la mujer sólo le entrega características del lugar, pero no le dice claramente lo que es, ni él posee la experiencia para reconocer sus connotaciones- le trae aparejado el castigo. En una siguiente etapa debe trabajar, para integrar por sí solo, a su propia experiencia, lo que el término significa. Más bien, resignificar el término a partir de su experiencia, ya que el niño desconocía la palabra, pero ya antes de saberla existía un ámbito experiencial que esa palabra podía denominar. Lo que quiero asentar aquí, es que la escena recién descrita de Vidas secas nos ayuda a comprender a la infancia como un territorio de entrada al lenguaje, cuyo proceso lleva aparejado juegos de poder, exclusión e inclusión, una carga traumática investida en la traducción, y la concepción del lenguaje como un lugar de encuentro entre lo dicho y lo significado, en el que los alcances de la metáfora y la metonimia (el niño usa la palabra para nombrar mucho más que lo que infierno, en estricto rigor, significa), cuyos límites se erigen para ser traspasados. En este caso, además, este proceso se sitúa en un contexto de total carencia, en la representación del subdesarrollo y la injusticia social, promoviendo una lectura de la palabra como continente insuficiente -y por ello tan ávido de recursos literarios que lo abran como significado- para denominar y comprender su situación.

Como ya adelanté, las cintas que me interesa revisar incluyen además otro componente relevante para el análisis: ambas tratan el problema del lenguaje vinculado a minorías étnicas (además de presentar niños involucrados en este escenario sociocultural), lo que entrega un giro productivo en relación al asunto de la lengua, al poner en relieve las reivindicaciones y luchas de agrupaciones indígenas por preservar y resguardar su patrimonio idiomático, enfatizando de esta manera su importancia como armas culturales. Pero también, ambas deben hacerse cargo del problema de la traducción, en la medida que integran un código no necesariamente compartido por el espectador al que va dirigido, y deben por lo tanto, utilizar subtítulos. El subtitulado se integra al filme en un estatus de palabra-imagen o image-text (según el concepto de W.J.T. Mitchell al que me referiré más adelante), reforzando la inscripción visual 
de la palabra en diálogo con las demás imágenes en la pantalla, a la vez que resalta las aspiraciones pedagógicas o didácticas que cada cinta quiere alcanzar. Siguiendo a Ian Balfour y Atom Egoyan en la introducción de su libro Subtitles. On The Foreigness of film, los subtítulos no son ya una mera herramienta en función de un fin sino en sí mismos parte del paisaje visual de cada obra cinematográfica, a la vez que refuerzan el carácter "extranjero" de todo filme, sobre todo en una cultura cada vez más global.

El primer filme a revisar es Shunko (1960) de Lautaro Murúa, largometraje de ficción realizado en Argentina, donde me centraré principalmente en la noción del sujeto colonial como niño y el uso -y la falla- del subtitulado, entendiéndolo como elemento significante.

El segundo es el documental Dungún, la lengua (2012) de la realizadora chilena Pamela Pequeño, donde también indagaré en el uso de subtítulos, pero ahora centrándome en el diseño de una estructura de autoridad basada en esta "voz" articulada visualmente y cómo el filme cuestiona o apoya dicho espacio autoritario en el uso que hace de ellos, explorando de qué manera refleja o esconde el entramado en que se asienta una cierta lógica de dominación.

\section{Shunko: el sujeto colonial como niño y la palabra como imagen}

En esta parte, y a fin de reafirmar mi aproximación a los usos instrumentales de la traducción en el cine como componentes significantes del filme en su relación con las representaciones y conceptualizaciones de la infancia, quisiera ahondar en esta cinta argentina y su manejo del subtitulado. Shunko es una breve novela de Jorge W. Abalos, en la que el autor narra su propia experiencia como profesor en una escuela en la zona rural de Santiago del Estero en Argentina, donde convive con hablantes nativos del quechua. Lautaro Murúa, actor y director de cine nacido chileno pero quien desarrolló su carrera en Argentina, decidió llevarla a la pantalla grande, con un guión adaptado por Augusto Roa Bastos (el cual sufrió varias modificaciones durante el rodaje). Una de las decisiones del director que llaman la atención respecto de la película es la de mantener algunos diálogos en la lengua de los protagonistas (los niños actores son habitantes de la zona) y subtitular estas escenas. Influenciado principalmente por el estilo de Leopoldo Torres Ríos, marcado por una tendencia a la simplicidad y la ternura que bordean el sentimentalismo, así como por el estilo realista y una meticulosa atención a los detalles, Murúa optó por utilizar el sonido directo y conservar el uso de la lengua autóctona (Barnard y Rist 33).

El texto literario en que se basa el filme (cuyo formato es epistolar, como dos breves misivas dirigidas por el maestro a su antiguo estudiante, Shunko, en medio de las cuales se desata el cauce del recuerdo que construye la historia), también incluye palabras en quechua, y para guiar al lector en su comprensión, al final del libro hay un "Pequeño vocabulario de la lengua quichua que se habla en la región central de la 
provincia de Santiago del Estero". Así como la experiencia de lectura de esta nouvelle estará marcada por las visitas (o no) a esas páginas finales ${ }^{4}$ para traducir aquellos vocablos que el hispano-hablante no domina, la experiencia de visionado del espectador del filme también acusará la presencia de las palabras desconocidas y su traducción en la porción inferior de la pantalla. La diferencia tal vez sea que aún cuando el "Pequeño vocabulario" es parte consustancial del libro, quien no quiera consultarlo puede simplemente no dirigirse a esa sección, mientras que el espectador, incluso si se resiste a su lectura, tendrá la mancha jeroglífica ante sus ojos permanentemente, como otro integrante del paisaje fílmico.

Quisiera proponer entonces, que el uso del subtitulado y su necesidad, dada la decisión de conservar los textos en lengua quechua, conlleva principalmente dos derivaciones: una, constata la importancia otorgada por el filme a los textos/diálogos, esto es, el habla desplegada en las escenas en la dimensión de su contenido; y dos, otorga a dicho recurso una materialidad que dialoga con el resto de las imágenes y figuras que lo habitan. Así, quiero iniciar mi análisis desglosando aquellas escenas en las que el habla vernácula se torna un elemento importante -y por ende se subtitula-y desarrollar luego mis consideraciones al respecto.

Un detalle significativo es el hecho de que solo los niños hablan en quechua. Los adultos hablan en español entre ellos y generalmente también con los niños. En escasas excepciones los adultos utilizan la lengua originaria, pero solo para dirigirse a los niños. Antes de hacer un examen de los usos particulares que se da a estas pocas inserciones de lengua nativa, quisiera establecer un cruce teórico entre la posición que el quechua ocupa en la película como lengua de la infancia y el sujeto colonial como niño.

El análisis de la figura del sujeto colonial como niño ya ha sido trabajado previamente. Sobre este asunto reflexioné de manera más extendida en "Tire dié: niño que habla", trabajo dedicado a estudiar los alcances del uso del doblaje en una cinta paradigmática para el tema de la infancia marginal en el cine latinoamericano, el famoso documental de Fernando Birri, Tire dié. En esta ocasión no profundizaré sobre el punto, pero me interesa dejar establecido que ya en escritos fundamentales de la teoría postcolonial como Piel negra, máscaras blancas de Frantz Fanon, se puede encontrar la analogía entre el colonizado y la figura del infante, comparación que opera como mecanismo de dominación. Así también la internalización de esta figura por parte del sujeto colonial lo lleva a plantear una mímica del "adulto", encarnado en la cultura colonizadora, incluso en el proceso de su propia emancipación, como expresa Bill Ashcroft en su ensayo "Primitive and Wingless: the colonial subject as child".

Volvamos ahora al filme. Como dije, sólo los niños hablan en quechua y en algunas oportunidades los adultos hablan en quechua con los niños. En ninguna escena

4 También se incluyen traducciones en formato de notas al pie, pero no para todos los términos en lengua indígena. 
de Shunko tenemos a dos adultos usando la lengua originaria para comunicarse entre ellos. Los niños la usan generalmente en conversaciones cotidianas, refiriéndose a hechos triviales de su diario vivir, especialmente Shunko, el protagonista, y su amiga Reyna. En dos ocasiones la lengua es utilizada por niñas, Reyna y otra pequeña no identificada por su nombre, para llamar la atención sobre un hecho excepcional, llamativo o peligroso, como el hallazgo de una maravilla natural en el primer caso, o la presencia amenazante de una víbora venenosa en el segundo. Podemos resumir que la función de la lengua nativa es, en los niños, preeminentemente comunicativa, para establecer relaciones y denominar el mundo que los circunda; y que en la película se encuentra asociada al mundo infantil.

Veamos ahora cómo la utilizan los adultos. La primera vez que un adulto habla en quechua se trata del maestro que intenta poner orden en la clase. Luego de este episodio, en otras ocasiones inserta vocablos nativos en su diario quehacer como docente. El habla originaria lo sitúa en un rango de reconocimiento frente a la comunidad, que en un principio lo rechaza. Saber su lengua lo favorece con una valoración positiva de parte de los niños a los que educa y de sus familias. "El hombre es bueno y habla quichua", le dice Reyna a su amigo Shunko, refiriéndose al profesor. Sabemos desde Antonio de Nebrija hasta Michel Foucault que la lengua es una herramienta de poder. En este caso, el maestro, cuyo lugar en la escala social es de mayor jerarquía que la de los habitantes de este pueblo alejado de las urbes, su cultura y sus comodidades, y cuya lengua materna -el castellano- contribuye a reforzar esta posición, se ve enfrentado a una alteración de ese orden. Para ser aceptado por el grupo al que se acaba de integrar y con quienes necesita negociar a fin de poner en práctica su saber y su definición social -enseñar, ser maestro-, requiere manejar, al menos instrumentalmente, la lengua originaria de la zona. En este cruce espacio-temporal es el quechua el que lo investirá de poder y reconocimiento, no el castellano.

Hay dos excepciones para lo que señalé anteriormente acerca del uso del quechua en la película. En dos ocasiones sí hay intercambio de palabras en lengua nativa con dos adultos presentes. Digo intercambio de palabras porque no son propiamente conversaciones. La primera de ellas nos ayuda a reforzar lo que acabo de desarrollar acerca de la lengua quechua como instrumento de poder en el filme. Se trata de uno de los encuentros entre Rufina, la mujer que le ayuda al profesor con las labores domésticas, y el maestro. Ella usa las palabras nativas no para comunicarse con él, ya que su conocimiento -el del profesor- es poco menos que mínimo, sino justamente para enseñarle. Él sabe que necesita de ese saber para ganar autoridad entre sus estudiantes, y le pide que le enseñe. En esta escena, el profesor se transforma en alumno, y es la mujer del pueblo quien maneja un elemento de poder que accede a compartir. Lo que quiero establecer aquí es la importancia de la lengua nativa como saber jerárquico en el filme, que invierte el patrón colonial en el que el castellano, como habla del colonizador, se erige como lugar de poder, y así repite la lógica infante/adulto. 
Como acabo de mencionar, hay otra escena en la que hay un adulto - otra vez el maestro- integrado a una situación en la que otro adulto se expresa en quechua. Pero tampoco se trata de una conversación entre los mayores y ahora veremos por qué. Luego de un eclipse de luna acontecido en el lugar donde se desarrolla la película, el profesor intenta explicarles a sus estudiantes las razones científicas del fenómeno: uno de los niños, Shunko, le aclara que ellos tienen otra explicación para lo que la comunidad llama "la muerte de la luna", y que sólo puede revertirse a través de un ritual llevado a cabo por los lugareños. Cuando el profesor intenta comprender cuál es la relación entre las características del rito y la vuelta a la vida de la luna, Reyna le señala que hay una mujer en el pueblo que conoce esa relación, ya que "ella sabe todo". El grupo en su conjunto visita a la anciana y es esta la única escena de la película que sugiere una cierta textura documental. La mujer es claramente una habitante del pueblo, de hecho, es la única adulta con un personaje de mediana relevancia que no es actor o actriz, y su relato surge entonces como el único texto hablado en quechua que no tiene una vinculación directa con el entorno -como las conversaciones entre los niños-, si no que elabora una narración, y es por lo demás el más extenso (todas las conversaciones entre los niños y entre adultos y niños se reducen a frases breves y expresiones aisladas).

El relato de la anciana, cuya duración es de poco más de 30 segundos y no es interrumpido por ningún otro diálogo, está íntegramente subtitulado al castellano. Al principio del capítulo y luego al inicio de este apartado, hice referencia a la significancia del subtitulado como recurso de traducción, en cuanto componente legítimo del filme. Quisiera ahondar en el análisis de esta escena partiendo de dicho postulado, y estableciendo así una vinculación entre el subtitulado como imagen y el resto de los elementos visuales en la escena, pero siempre en diálogo con el material sonoro que en primer término lo genera. Para ello, me propongo sostener mis apreciaciones en la noción de imagetext desarrollada por W.T. Mitchell, como concepto clave dentro de los estudios visuales. Como el mismo Mitchell lo señala, la imagetext, más que un concepto, aspira a ser una figura teórica, un lugar de tensión dialéctica entre la imagen-lo visual- y el texto -la escritura-. Antes de intentar una exploración de la escena en particular, quiero confrontar los aspectos relacionados con la lengua como saber/poder y la propuesta de Mitchell. Uno de sus puntos de partida es la concepción derridiana desarrollada en De la gramatología, de la escritura como huella material que descentra el modelo fonocéntrico, otorgando así un estatuto visual -y no sólo conceptual, sino de esta manera, material- a la escritura. Lo que quiero poner en tensión aquí son las estructuras de poder que se desprenden de este cuadro teórico. Por una parte la lengua como fonología pierde su lugar preponderante al poner atención en la visualidad/materialidad de la escritura, y por ende, considerarla una imagen. En este sentido, el paradigma que se subvierte es el que considera a la imagen como el medio del subhumano, el salvaje, el animal inferior, el niño, la mujer, las masas (Mitchell 24. Las cursivas son mías), mientras la palabra es el medio usado por el hombre (civilizado, adulto, blanco y educado). Desde otra perspectiva, la lengua como figura 
escrita se contrapone con el habla como oralidad, de manera que en este segundo cuadro la escritura, la imagen, tiene un lugar preponderante por sobre la sonoridad plebeya del lenguaje hablado. Establecido este punto de inflexión en el que la palabra como escritura/imagen/visualidad comporta una doble posición jerárquica frente a su versión acústica, intento ahora volver a la escena antes descrita.

El subtitulado de la escena en que la mujer anciana explica a los niños y al maestro la muerte de la luna es, como en el resto de la cinta, blanco. La ropa de la anciana es blanca también, y también lo es la de la niña que se sienta a su lado. El efecto visual es, así, la falla del subtitulado en su función traductora, ya que las palabras se pierden en el fondo blanco y no vemos más que imágenes desdibujadas, sumergidas a medias en el "papel" que las contiene. Es posible reconocer algunas palabras en los bordes de la pantalla, aquellas que no están sobre el cuerpo de la narradora, y con ellas armar un puzzle que nos da una idea vaga de lo que su discurso contiene, pero que no termina de descifrarse. De esta manera, el texto, es aquí casi pura imagen, pura materialidad, cruzada con ciertos atisbos de significación, pero que no alcanzan a construir un edificio acabado de contenido. En este juego visual las palabras parecen perderse en quien las emite, y su sonoridad alcanza un rango prominente. Hay aquí también otro cruce con uno de los parámetros más recurrentes a la hora de posicionar a la escritura por sobre la oralidad: su fijeza, su permanencia. La escritura, en este caso el subtítulo, pierde su fijeza porque es devorada por el cuerpo de la mujer -también materia- desde donde surge la voz, que sí supervive como significado a su reproducción técnica, y se solaza en la fugacidad que la constituye (aún cuando en este caso es un habla que perdura, ya que ha sido grabada). En un filme cuya temática refiere repetidas veces a la permanencia (el profesor se va pero se queda en su enseñanza, la niña que muere vuelve como espectro a buscar su libro de estudios), y que intenta, a veces un poco ingenuamente, dar preponderancia a la cultura ancestral, esta escena podría constituir un contrasentido: el saber de los pueblos originarios es respetable y valioso, pero desaparece.

Al final de la escena, y ya que la cámara realiza un paneo de la concurrencia que rodea a la anciana, en las ropas oscuras de los niños y del profesor, se pueden reconocer algunas palabras y, muy claramente, la última frase: "pero es inmortal". Los hispanohablantes, esto es, los espectadores potenciales del filme (en otro caso se habrían subtitulado también los diálogos en castellano), casi no pueden captar ninguna oración completa de la oración de la mujer, salvo este pequeño texto. Parece decir, al ponerse en relación con lo explicado anteriormente, que esta cultura ancestral, que se fuga en la oralidad, que va quedando vaciada de sentido como concepto, permanece en otras formas, otros saberes, porque es inmortal. Una curiosa coincidencia en la falla del subtitulado.

Quiero confrontar ahora esta escena con otra, en la que también una mujer mayor desarrolla un discurso frente a una audiencia. Se trata de una profesora de la ciudad, que ha invitado a los niños del pueblo a participar en un acto de homenaje a Sarmiento. El personaje, que además de oponerse a la mujer anciana porque es 
letrada, vive en la urbe y habla español, se distancia de ella en términos del tratamiento del personaje. Como señalé antes, la escena de la anciana tiene ribetes de documental, pues aunque la puesta en escena es parte del guión de la película, la mujer no actúa -ni tampoco es actriz - sino que narra, en su voz y con su saber, una leyenda probablemente escuchada por ella de voz de otras mujeres de su pueblo. La maestra de la urbe, por el contrario, llevada a escena por una actriz profesional, está construida como una caricatura de sí misma, para ser rechazada por el espectador, en cuanto a su ignorancia y prepotencia frente a los valores populares. Su texto es el de un discurso ceremonioso, rebuscado y caricaturizado también, que aburre a los niños. Cuando salen del acto oficial, y tal vez influidos por el nada atractivo discurso antes escuchado, Shunko y uno de sus compañeros se burlan, sacándole la lengua, de un monumento a Sarmiento. La toma es un cuadro en picado en el que la estatua de Sarmiento observa desde lo alto la acción difamatoria, y los niños revierten su posición de inferioridad en la mofa a la figura de poder. En este fragmento, una de las declaraciones explícitas de la película -Sarmiento como el fundador de escuelas y gran maestro, modelo para el profesor de Shunko- se desvirtúa, convirtiendo al filme en una doble proclamación de preponderancia de la educación formal y el saber racional-científico, y de su propia negación.

No es menor que la película haga mención a Domingo Faustino Sarmiento, tratándose de uno de los promotores, a través de su libro Facundo, de la concepción del indígena como un ser inferior, infantilizado, a quien se requiere controlar y modelar. No creo que el filme tome partido en este sentido, si no que me parece que, especialmente en la escena de la mujer anciana que relata la leyenda de la muerte de la luna, tenemos, gracias a la presencia del subtitulado como marca material en diálogo con los demás elementos de la secuencia, una muestra de la tensión latente de un conflicto no zanjado. La falla del subtitulado y la posterior interpretación que de su resultado realizo aquí, pretendo situarla más bien en la tensión constante y no resuelta de la "heterogeneidad" latinoamericana, descrita por Antonio Cornejo Polar. En su estudio, y al renunciar a una descripción "uniforme, complaciente y desproblematizada" de la cultura de América Latina, Cornejo Polar funda un pensamiento que se basa en el conflicto no resuelto que enmarca nuestro entramado social, el cual es

(...) de una violencia extrema y de una extrema disgregación. Aquí todo está mezclado con todo, y los contrastes más gruesos se yuxtaponen, cara a cara, cotidianamente. Visceralmente dislocada, esta intensa comarca social impone también, como materia de la representación verbal, códigos de ruptura y fragmentación [...] realidad [de] ejecución reiterada de injusticias y abusos, ocasión siempre abierta para discriminaciones, maquinaria que insume y produce miserias insoportables. (22)

Así, la película, en su afán por reivindicar la cultura originaria -y con ella al sujeto colonial infantilizado y negado en su potencialidad de ser humano adulto de pleno derecho- opta por utilizar subtítulos que traduzcan, conserven y propaguen la voz de 
la mujer que la representa. Pero ello ocurre siempre desde su "versión" revisada del idioma castellano, que no puede contenerla completamente -como toda traducciónde la misma manera que la integración de la cultura indígena por parte del discurso oficial pasa por su simplificación o reducción. Pese a la intención primaria, la falla en el material técnico, su parcial invisibilidad, no hace sino recordarnos que bajo la ingenuidad del discurso políticamente correcto, subsiste un discurso violentado, acallado, que se escribe en el aire y en éste se disipa, pero que sin embargo es inmortal. El desperfecto que vuelve el texto ilegible es a la vez la violencia de la anulación y los resquicios por los que ese discurso doblegado permanece en su fugacidad. Los subtítulos, la letra, resguardan a la vez que coartan la oralidad primigenia del discurso de la mujer. Los únicos que pueden entenderla son los niños y el músico que toca la guitarra mientras la mujer habla y que, ya se nos ha expuesto, atrae con su música a los niños .La película parece pasar por alto que el profesor es incapaz de entender cuál es la leyenda que la anciana narra. Los niños son los que hablan en quechua, los portadores del castellano imperfecto, y el músico el representante del sonido sin concepto. La voz de la mujer sobrevive como sonido y como mancha que se sumerge en la materia, previa al lenguaje. Así, el sujeto colonial sigue atrapado en la categoría del in-fante, del que no habla, del que habla a medias, pero sin embargo su discurso posee un enigma que se nos niega resolver, y es en él donde pervive. Y el espectador se queda sin compartir, más que como sonido ininteligible, lo que allí se acaba de decir.

\section{Dungún, la lengua como ejercicio de autoridad}

El segundo documental de la realizadora chilena Pamela Pequeño se hace cargo de registrar el proyecto educativo llevado a cabo por Elba Huinca, una mujer de origen mapuche que da clases de mapundungún en una escuela primaria de la comuna de Lo Prado. El filme retrata también, como una especie de doble en las sombras, su relación con otra mujer, Olga Márquez, profesora básica, quien dicta clases regularmente en esa escuela y que la apoya en el aspecto más pedagógico de las sesiones de lengua que Elba imparte. Las clases en general aparecen levemente caóticas y marcadas sobre todo por un contexto bilingüe, en que la maestra mapuche intercala vocablos y conceptos de su lengua materna ${ }^{5}$ en un diálogo principalmente desarrollado en castellano. Esta falta de solemnidad que parece circundar el ambiente del salón de clases, dialoga muy bien con una intención de la película, explicado así por Viviana Erpel, su productora, en una nota aparecida en Diario La Tercera:

5 Hablar de "lengua materna" en este caso significa referirse a la lengua de sus padres, pero que ellos mismos reprimieron en el seno familiar, para evitarles a sus hijos la discriminación que ellos sufrieron. Elba aprende mapundungún solamente porque lo escucha, aunque tiene prohibido hablarlo. El estatus de "primera lengua" es problemático, ya que la que usa diariamente durante su infancia es el castellano, el idioma oficial. 
(el documental) apunta a legitimar y revalidar lo que durante mucho tiempo se ha negado esquizofrénicamente en nuestras sociedades y es el ser indígena. Es cierto que gran parte de nuestro continente es mestizo, pero es trascendente para la salud mental y espiritual de nuestros pueblos el no sólo sentir interés por la ascendencia europea sino también saber reconocer cuánto de indígena está presente en nuestro árbol genealógico (“En Festival de Valdivia se estrena documental.... Web)

Como bien señala Carmen Hernández en su artículo "Chile a fines del siglo XIX: exposiciones, museos y la construcción del arte nacional”, una de las fantasías más recurridas en la construcción del imaginario nacional en los inicios de la república era la de relegar al pasado remoto de la historia americana las tradiciones y la cultura de los pueblos originarios, situándolo en las instituciones de resguardo del patrimonio nacional -los museos principalmente- en un reducto pretérito e inmóvil, sin ponerlo en diálogo con su presente y con los intercambios que seguían sucediéndose con otras culturas y otras tradiciones. Las culturas indígenas eran el origen, la historia primitiva, y debían permanecer ahí. Así, Dungún, la lengua, posiciona a la cultura mapuche, encarnada aquí en Elba y en su vínculo con Olga, la maestra huinca ${ }^{6}$, no en representaciones de lo heroico anclado en el pasado, sino en una anti-épica que se inserta en los intersticios de lo cotidiano. Podemos reconocer esta inscripción ya desde el inicio de la película, cuando un fondo musical de instrumentos indígenas ilustra la imagen del despertar de la ciudad de Santiago acosada por el smog y una suave bruma matinal. Es el contrapunto de ambas imágenes (la visual y la auditiva) lo que genera un sentido contradictorio pero productivo respecto del estatuto de la cultura mapuche inserta en la urbe y separada del estereotipo que la condena a ser una pieza de museo.

En otro sentido, pero también en referencia a aquello no evidente que el filme retrata, el documental nunca hace referencia explícita al llamado "conflicto mapuche" que especialmente durante el año de su producción y estreno ha cobrado relevancia mediática -más gracias a las redes sociales que a los medios de comunicación tradicionales-, con la visibilización de varios comuneros en huelga de hambre y la cobertura de la violencia ejercida en las comunidades mapuche por parte de las fuerzas policiales. Sin embargo, la cuestión del atropello cultural, material y físico ejercido sobre un grupo no aparece sino como un contenido latente, una música de fondo apenas audible pero no por eso muda, distanciándose así de otras realizaciones chilenas relativas al tema indígena, como el documental Newen Mapuche de Elena Varela.

Ahora, lo que me interesa destacar es cómo el uso de los subtítulos se integra a la mirada creada por el filme, y cómo se puede analizar en cuanto material significante. Lo primero que hay que establecer es que la utilización del recurso traductor ocurre de

6 Huinca es el vocablo en mapudungún que sirve para denominar al extranjero, al colonizador. Es curioso que ese sea justamente el apellido de la protagonista, que en un involuntario juego irónico, parece representar esa doble inscripción que la sitúa en medio de la cultura dominante como una bisagra lingüística. 


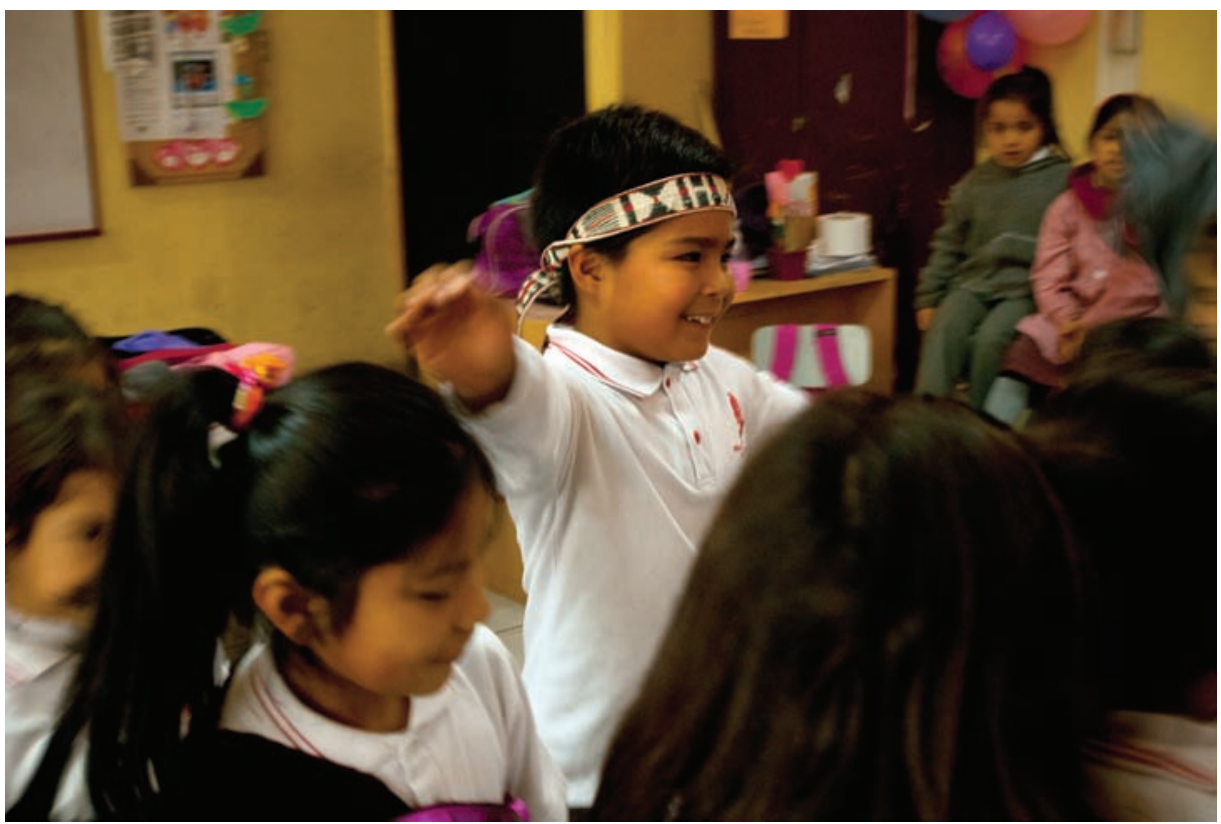

Dungún, la lengua (2012) de Pamela Pequeño.

manera tradicional, como herramienta pedagógica que asegure la cabal comprensión y decodificación de los mensajes elaborados por Elba Huinca durante sus clases, o por otros personajes que eventualmente se comuniquen en la lengua vernácula. En ese contexto, los espectadores reforzamos nuestro lugar de alumnos que aprenden no solo un discurso revelado por el filme, sino que también específicamente las palabras que Elba repite y que el subtitulado traduce.

Uno de los elementos relevantes respecto del uso de subtítulos tiene que ver con la estructura del documental. La cinta está segmentada en cuatro partes, cada una correspondiente a una estación del año, identificadas todas ellas en la lengua materna de Elba. Esta decisión enfatiza la importancia de la cosmovisión mapuche al organizar las estaciones según el año nuevo indígena, que marca la primavera - pewü-como inicio, y no el primero de enero, como está estandarizado en las sociedades occidentales. En este primer gesto, la organización pero también el uso del vocablo autóctono, ubica al espectador como un eslabón del proceso pedagógico y pone el acento en la autoridad del recurso traductor ubicado en el subtitulado.

Ahora, lo que aquí denomino subtítulo funciona de dos maneras: cada una de las estaciones está individualizada en textos en el idioma original, que a su vez conviven con los respectivos subtítulos que los traducen al castellano. Estos subtítulos -los primeroscorresponden en verdad a lo que en inglés se denomina intertitles, y que puede hacer referencia a los créditos u otros textos funcionales para el desarrollo de la respectiva 
cinta (paso del tiempo, reconocimiento de lugares, etc.). En su artículo “The Use and Abuse of Subtitles", Amresh Sinha, enfatiza esta diferencia sobre todo para cuestionar la supuesta artificialidad de los subtítulos (como herramienta de traducción), en oposición a los intertitles o intertítulos, que como espectadores aceptamos con naturalidad, como si pudiéramos realmente hacer una diferencia tan tajante entre aquello que pertenece al filme y aquello que amenaza su supuesta pureza. Este encuentro de las dos categorías de textos (visuales) dentro del documental que me ocupa, me es útil para reforzar una primera idea ya expuesta al principio - la del subtítulo como elemento que conforma al filme en todos sus niveles- así como para situar el concepto de autoridad que quiero instalar como relevante en el análisis. Puse ya atención en la función pedagógica que los subtítulos tienen en este trabajo de Pamela Pequeño. No podemos desatender que se trata de una película acerca de la enseñanza y que en mi aproximación a la infancia intenté resaltar el aprendizaje de la lengua como un territorio de conflictos y desencuentros. En Dungún, la lengua, el proceso de enseñanza pasa por distintos niveles: Elba educa a los niños, Olga educa a Elba, Elba y Olga educan a los padres, los hijos educan a los padres, una institución educa a Elba y la "autoriza" como genuina hablante de su propia lengua materna y, por último, el filme educa a sus espectadores.

Como ya señalé, el documental se sitúa en una manera de entender lo pedagógico más bien tradicional, sobre todo si pensamos en el modo cómo se utilizan los textos subtitulados. Así, se da por sentada esa "autoridad" del polo que entrega el conocimiento. Tal como la institución a la que Elba asiste, o la escuela en el caso de los niños, los subtítulos nos instruyen acerca de un conocimiento que es delimitado y preciso, que al ser traspasado por quien detenta la autoridad, a su vez "autorizan" a quien no la detenta. Esta es una concepción que está en declarada pugna con la propuesta de enseñanza desarrollada por Jacques Rancière en El maestro ignorante, que trata de enfatizar el poder auto-emancipatorio contenido en la inteligencia del alumno, y el peligro de las restricciones que pone la pedagogía. No quiero entrar a detallar su propuesta analítica, pero sí creo relevante destacar uno de los puntos centrales de su discurso. Siempre, nos dice Rancière, hay un tercer elemento que media entre el maestro y el alumno, ese tercer elemento no le pertenece a ninguno y es el que permite que el maestro enseñe algo que no sabe. Tal como vimos ocurre en la escena de Vidas Secas, el sentido que es generado por el niño supera y desborda el vocablo recibido. Una noción de pedagogía basada en la autoridad no puede hacerse cargo de ese excedente, de por sí productivo, aun cuando pueda ser problemático e incluso doloroso en el contexto de la película. Eso es lo que me interesa explorar en el documental, la manera cómo el subtítulo no es capaz de contener las contradicciones y vacíos del proceso de adquisición del lengua, y cómo en su ineficacia se vuelve más interesante. Para ello me propongo revisar en qué secuencias podemos reconocer la relación del subtitulado con estas contradicciones y vacíos.

Antes de analizar los ejemplos quiero integrar un concepto más, también señalado por Amresh Sinha, pero acuñado por Gayatri Chakravorty Spivak al abordar la 


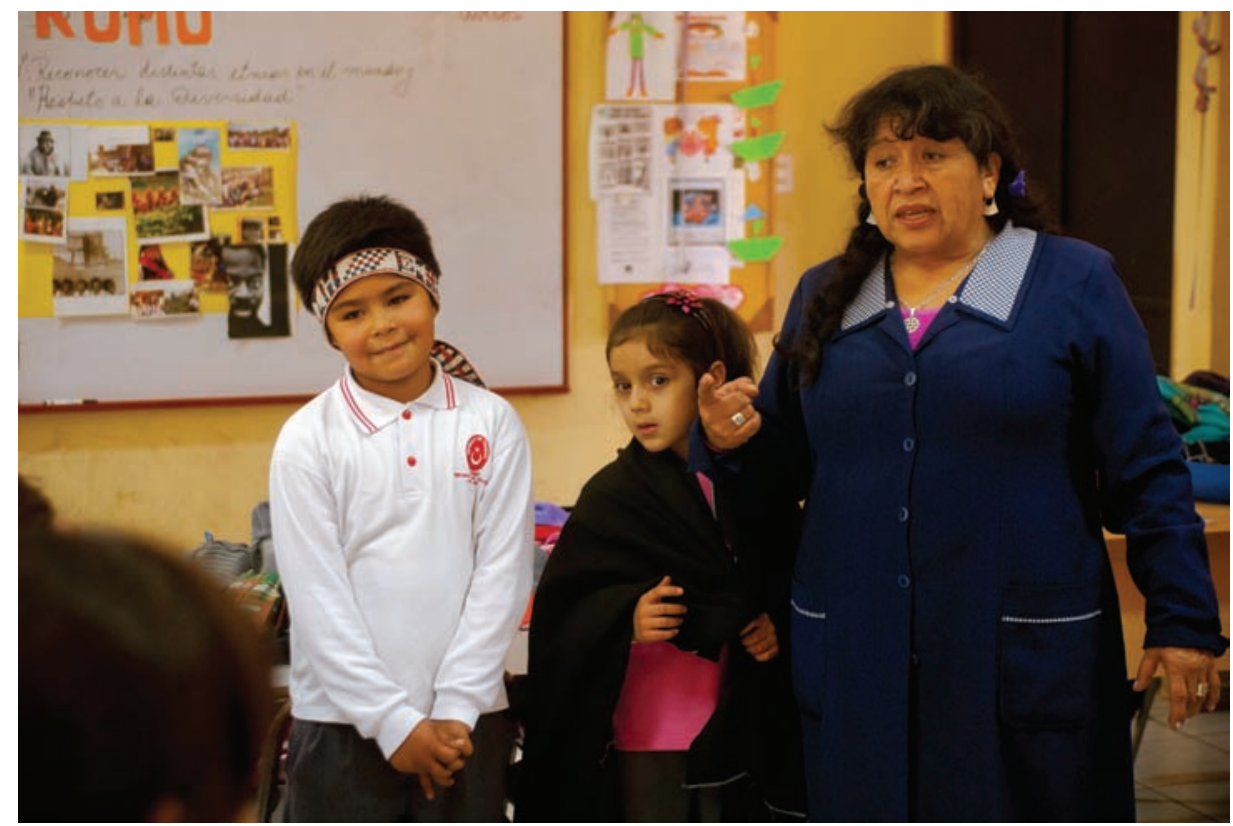

Dungún, la lengua (2012) de Pamela Pequeño.

traducción en "The Politics of Translation", quien opone a la ansiada fidelidad (fidelity) al texto original, la idea de amor (love). Entendiendo la mencionada fidelidad como un arma que restringe cualquier transgresión en la relación entre el texto y quien lo lee, y no colabora en la comprensión de la traducción como el acto de lectura más íntimo, en el que entra en juego más lo erótico que lo ético (185). Su idea de "amor" en el contexto de la traducción, permite asumir ese desborde contenido también en el proceso de aprendizaje de una lengua, en la medida que es también un acto de traducción entre las palabras y la experiencia, en el que todos somos, como niños, extranjeros en el lenguaje.

Los primeros ejemplos se relacionan con la idea de contradicción que mencioné antes. En estas escenas se retrata claramente el bilingüismo de Elba (y de sus familiares) y las fallas en el aprendizaje de parte de los niños. La lengua es algo que está pero a la vez se esconde y muta; en el caso de Elba, porque ha sido enseñada desde una lengua materna que fue reprimida y una lengua adoptiva que es a la vez la que instaura la prohibición. En el caso de los niños, porque se integran al habla mapuche dando tropiezos y esa misma falla promueve una lectura menos autoritaria del propio proceso de incorporación a la lengua. Voy a comenzar por el primer caso.

Cuando Elba habla con los niños integra vocablos en mapudungún y en castellano, sus frases son puzles idiomáticos, para los que el subtitulado resultado ineficiente, pero por lo mismo pone en relieve esta disputa: "mi ñuke", "mi chuchu" (por "mi mamá", "mi abuela"), "los pichikewentru, las pichikedomo" (por los hombres, las 
mujeres), son pequeños ejemplos. El mecanismo de traducción aparece y desaparece, porque refuerza algo que ya está ahí a la vez que intercambia lo que no es entendible por los hablantes del castellano. Seguramente la escena que mejor ilustra este punto es el encuentro de Elba con su tía. Todos quienes están ahí como personajes entienden y hablan el idioma mapuche, sin embargo, la mujer se expresa en una mezcla difusa que viaja desde su lengua originaria al castellano y luego vuelve. Su bilingüismo pone en evidencia a un subtitulado que ya no puede operar como simple herramienta funcional, porque la propia dislocación de la lengua lo impide, no hay ahí solamente un contenido que traducir, sino que también el encuentro belicoso entre sistemas culturales que se encarnan en el cuerpo de esa mujer.

Algo similar ocurre con los niños, algunos de ellos con padres o madres mapuche, pero que sin embargo desconocen su propia lengua. Elba se las entrega y ellos fallan, porque aprender es también fallar, recordándonos además que esa lengua vuelve a ellos, retorna, y ese retorno no es fácil. El subtítulo se hace aquí precario, pero en su falencia nos habla de lo que la simple traducción entendida como fidelidad no puede hablar. Podría haber sido una opción de Pamela Pequeño el problematizar esto desde el subtítulo como traducción amorosa (en el sentido que le da Spivak), como apertura o desafío de la autoridad contenida en cierta concepción de la enseñanza. Aunque ella no lo haga, los mismos procesos complejos retratados en el documental se enfrentan a las etiquetas demasiado estrechas que las letras de molde blancas les ofrecen. Eso es lo que he querido destacar aquí.

El último ejemplo tiene que ver con la idea de vacío y por lo mismo se encarga de abordar una instancia donde el subtítulo no aparece, por innecesario, aunque hay también un encuentro de sistemas de comunicación, una especie de versión lata de lo que entendemos por lenguaje. La cultura mapuche no tiene el aplauso como forma de celebrar o expresar sonoramente su opinión o aprobación. En lugar del aplauso se usa el afafa, sonido vocalizado que Elba trata de enseñar a la audiencia que acaba de ver a sus hijos presentando una danza tradicional mapuche en el día que la escuela celebra el Año Nuevo indígena. Sin embargo, aun cuando ella acaba de aclarar que "los mapuche no aplauden, así que vamos a hacer un afafa, lo que yo les enseño siempre", y los niños lo repiten dos veces, la conductora del acto, ataviada como mapuche pero cuyo estilo de conducción está apegado a la estética televisiva más tradicional, señala: "un aplauso para Elbita, que es tan linda". Al instante corrige, ante la mirada atónita y luego amablemente reprobatoria de Elba: "un afafa, no era aplauso". Aquí no son necesarios los subtítulos, porque lo que se expresa no son palabras, sino sonidos, que sin embargo contienen también sentido -y por eso no significan lo mismo en una cultura o en la otra-. El subtitulado pudo hacerse cargo de ese sentido y no lo hizo. Solo nos dejó con la verdad desnuda de una enseñanza que se esfumó en el aire denso de una cultura dominante, que no acepta ser tratada como niño que es adiestrado en prácticas y conductas y que, por el contrario, sigue infantilizando a la cultura dominada incluso en el espacio en que intenta reivindicarla. 
El aporte de Dungún, la lengua es visibilizar estos asuntos, aun cuando no sea totalmente consciente de ellos, o no los haga evidentes como parte de su propia construcción. Sin embargo, la renuncia al discurso estereotipado, a las verdades absolutas, su intención de asomarse a ese cotidiano complejo y belicoso permite abrir al espectador una lectura propia y productiva. Por los intersticios por los que la cinta mira es posible asomarse a ver más.

Al inicio de este texto me propuse revisar la relación entre incorporación del lenguaje e infancia, en dos cintas que se aproximan a la infancia no solo en la medida que integran niños como personajes relevantes, sino en la medida que delimitan modos de ser infantiles en el proceso de enseñanza. En ambos casos me centré en el uso de subtítulos - esos parias, mezcla de imagen y voz, así descritos por Amresh Sinha- en la medida en que su falibilidad en Shunko o su uso autoritario en Dungún, la lengua, permitían leer entre líneas los conflictos y disputas asociados al lenguaje como lugar de intercambios, y por ende a la infancia como su territorio de guerra por excelencia.

\section{Referencias}

Abalos, Jorge W. Shunko. Buenos Aires: Losada, 2006. Medio impreso.

Ashcroft, Bill. "Primitive and Wingless: the colonial subject as child". On Postcolonial Futures: Transformations of Colonial Culture. London: Continuum, 2001.36-53. Medio impreso.

Balfour, Ian y Atom Egoyan. "Introduction”. Subtitles: on the Foreigness of Film. Cambridge: MIT Press, 2004. 21-30. Medio impreso.

Barnard, Timothy y Peter Reist. South American Cinema: A Critical Filmography 1915-1994. New York: Garland, 1996. Medio impreso.

Cornejo Polar, Antonio. Escribir en el aire. Ensayo sobre la heterogeneidad socio-cultural en las literaturas andinas. Lima: Horizonte, 1994. Medio impreso.

Derrida, Jacques. De la gramatología. México: Siglo XXI, 2005. Medio impreso.

Donoso, Catalina. “Tire dié: niño que habla”. Taller de Letras. No 51, segundo semestre, 2012. 219-234. Medio impreso.

Dungún, la lengua. Dir. Pamela Pequeño. Act. Elba Huinca, Olga Márquez. Hemisferio Derecho, TVN y DocTV Latinoamérica, 2012. "En Festival de Valdivia se estrena documental sobre enseñanza del Mapudungún”. La Tercera. 02 de octubre de 2012. 06 de noviembre de 2012. <http://www.latercera.com/noticia/ cultura/2012/10/1453-486263-9-en-festival-de-valdivia-se-estrena-documentalsobre-la-ensenanza-del-mapudungun.shtml $>$ Medio web.

Fanon, Frantz. Piel negra máscaras blancas. Buenos Aires: Abraxas, 1973. Medio impreso. Hernández, Carmen. "Chile a fines del siglo XIX: exposiciones, museos y la construcción del arte nacional”. Beatriz González Stephan y Jens Andermann (eds.) Galerías del progreso. Museos, exposiciones y cultura visual en América Latina. 
Rosario: Beatriz Viterbo Editora, 2006. 261-290. Medio impreso.

Mitchell, W.J.T. Picture Theory. Chicago: University of Chicago Press, 1994. Medio impreso.

Nichols, Bill. “Modalidades documentales de representación”. La representación de la realidad. Cuestiones y conceptos sobre el documental. Barcelona: Paidós, 1997. 65-114. Medio impreso.

Poto y Cabengo. Dir. Jean-Pierre Gorin. Act. Grace Kennedy, Virginia Kennedy. JeanPierre Gorin, 1979. Medio fílmico.

Rancière, Jacques. El maestro ignorante. La boca-Barracas: Editorial tieRra del sUr, 2006. Medio impreso.

Shunko. Dir. Lautaro Murúa. Act. Carlos Garay, Raúl del Valle, Lautaro Murúa. Producciones San Justo, 1960. Medio fílmico.

Sinha, Amresh. "The use and abuse of subtitles". Subtitles: on the Foreigness of Film. Atom Egoyan e Ian Balfour. Cambridge: MIT Press, 2004. 171-90. Vidas secas. Dir. Nelson Pereira Dos Santos. Act. Átila Iório, Maria Ribeiro. Sino Filmes, 1963. Medio impreso.

Recibido: 18 octubre 2013

Aceptado: 23 marzo 2014 